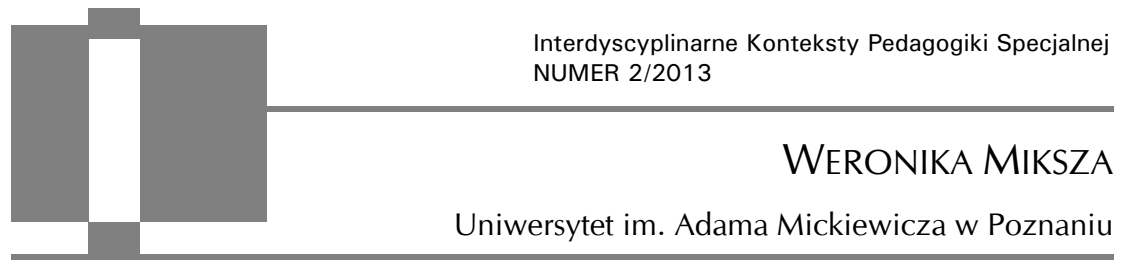

\title{
Teatr jednego aktora i czterech ścian
}

ABSTRACT: Miksza Weronika, A one-man and four-wall show [Teatr jednego aktora i czterech ścian]. Interdyscyplinarne Konteksty Pedagogiki Specjalnej, nr 2, Poznań 2013. Pp. 233-237. Adam Mickiewicz University Press. ISBN 978-83-232-2594-2. ISSN 2300-391X.

This article concerns hikikomori, which is an Asian phenomenon. It discusses this issue from different angles. The countries covered in the article include: South Korea, Japan, China, Singapore and other Asian countries. In addition this paper describes certain features of hikikomori as well as the phenomenon's origin. The ways in which hikikomori is presented in popular culture are also touched upon here. The conclusion at the end sums up all the key points in one paragraph.

KEY WORDS: hikikomori, Asian phenomenon

Każdy potrzebuje czasem spokoju. Bombardowani bodźcami i zawirowaniami życia codziennego chętnie zaszywamy się we własnych czterech ścianach. Cenimy sobie często rzadkie chwile dla siebie, które można poświęcić na: oglądanie filmów, czytanie książek, drzemkę, naukę słuchanie muzyki, surfowanie po Internecie, ślinienie się do fotek słodkich bishów czy milion innych kombinacji. Całości dopełniają wyjścia na zewnątrz w celach towarzyskich, ze zwykłej potrzeby albo $\mathrm{z}$ musu. Czasem konieczne są kontakty $\mathrm{z}$ rodziną lub proza życia w postaci domowych obowiązków. Bywa różnie, raz lepiej, raz gorzej, - ale ploty z kumpelami czy czekolada skutecznie zakopują dołki. Wydaje się, że wszystko gra - i słusznie. 
Co jednak, gdy cztery ściany stają się przystanią zbyt bezpieczną, by wyptynać $w$ morze? Co, jeśli nawet wstanie z łóżka to wyzwanie na miarę zdobycia Mount Everestu? A kiedy następuje społeczne odcięcie, nie wyłączając alienacji od najbliższej rodziny, to dobrze? Dla większości wydaje się to naciągane i straszne. Ale uwierzcie, że jak najbardziej możliwe. Aspołeczność niejedno ma imię, różnie się objawia i w każdym indywidualnym przypadku zupełnie odmiennie wygląda. Inaczej będzie się zachowywać osoba z zespołem Aspergera, inaczej z typowym autyzmem, a jeszcze inaczej ze zdiagnozowanym lękiem społecznym okresu dziecinstwa. Jednak opisywany przeze mnie problem, pokrewny wyżej wymienionym, ma typowo japońskie oblicze i określany jest powszechnie jako hikikomori.

Hikikomori, czyli w wolnym tłumaczeniu istota odosobniona lub odłączenie się to choroba cywilizacyjna o podłożu psychiczno-emocjonalnym, definiowana inaczej jako syndrom wycofania społecznego lub socjofobia. Autorem tego pojęcia jest japoński psycholog Tamaki Saito. Zaobserwowano je już w latach siedemdziesiątych XX w. wśród japońskich nastolatków, lecz wówczas określano mianem tôkôkyohi, czyli unikanie szkoły. Obecnie jej przejawy zauważa się u 0,5-1,2 mln Japończyków, a nawet u co dziesiątego młodego człowieka, choć przypadki zdarzają się teraz również w: Korei Południowej, Tajwanie, Chinach, Singapurze czy Hongkongu - państwach o systemie edukacji zbliżonym do japońskiego. Choć japońska szkoła ulega szlifowi idealizacji za sprawą anime i mangi, nie ma im w rzeczywistości czego zazdrościć; jest to edukacja na bardzo wysokim poziomie oraz uchodzi za jedną z najbardziej wymagających na świecie. Społeczeństwo japońskie określane jest mianem kyōiku shakai, czyli społeczności opartej na edukacji, w której status zależy od wykształcenia. Do dziś obowiązuje zasada pięciostopniowej edukacji; choć w 2002 r. skrócono tydzień szkolny do pięciu dni, co miało $\mathrm{w}$ założeniu odciążyć japońskie dzieci przeciążone obowiązkami i uzyskujące przez to gorsze wyniki. Nie zniknęło jednak piekło egzaminów wstępnych (shiken jigoku), nieodłączny pęd do bycia najlepszym, najpopularniejszym; temu służą wywieszane publicznie listy z wynikami, w skrajnych przypadkach nie- 
powodzeń - popełnianie samobójstw. Do takiego stanu rzeczy przyczyniają się też ambitni rodzice, w szczególności tak zwane mamy edukacji (kyōiku mama). W swojej gorliwości nierzadko chodzą za dzieci do szkoły, w razie ich choroby i uzupełniają dla nich notatki. Te objawy troski o przyszłość przybierają czasami chorobliwe rozmiary. W latach osiemdziesiątych pewna kobieta zamordowała córkę sąsiada całe dnie ćwiczącą grę na pianinie, przeszkadzało to bowiem $\mathrm{w}$ nauce jej synowi. Innym przykładem jest historia opisana przez Amy L. Chua w książce Bojowa pieśń tygrysicy - opowieść ambitnej, chińskiej matki, która wręcz tresowała swoje dzieci, każąc im grać na pianinie wiele godzin dziennie czy otrzymywać tylko najwyższe oceny. Nie wspomnę już o deficycie czasu wolnego oraz braku indywidualności w promującym współpracę systemie, na czym cierpi sfera emocjonalna nastolatków.

Jak wygląda typowy przebieg zjawiska hikikomori? Istnieje kilka jego rodzajów. Dla porównania napiszę najpierw słowo o typowym dniu japońskiego nastolatka. Modelowy przykład idzie do szkoły na godzinę 8:30, wraca około 15:30, potem wstępuje na zajęcia dodatkowe, po czym ma trochę czasu dla siebie i na własne przyjemności. Zmienia się to jednak od trzeciej klasy liceum; wówczas prawie 90\% nastoletnich Japończyków w ostatnim roku szkoły uczęszcza do juku - wieczorowych szkół dokształcających do egzaminów. Po zajęciach Japończyk w ostatnim roku nauki idzie do domu, je obiad i bierze prysznic, po czym zapada $\mathrm{w}$ drzemkę do około 1-2 w nocy. Potem wstaje, uczy się, znów śpi i rano do szkoły... Słowem: idzie w końcu zwariować. Nic dziwnego, że niektórzy Japończycy przytłoczeni presją uciekają w postawę hikikomori. Taki na ogół śpi cały dzień (znamienne przy depresji), czasem coś przekąsza ze zgromadzonych zapasów jedzenia lub podstawionych przez troskliwych rodziców, a w nocy ogląda telewizję lub gra w gry na konsoli, komputerze - co tylko ma w pokoju. Hikikomori może przybierać postać chorobliwego syndromu wycofania społecznego lub być indywidualnym wyborem. Pojęcie hikikomori jest również odnoszone do konfliktu między młodszym i starszym pokoleniem w japońskim społeczeństwie. Należy więc oddzielić bycie 
hikikomori z wyboru od zaburzenia. Osoby, które świadomie patrzą $\mathrm{w}$ ten sposób na świat, buntując się przeciw rzeczywistości, nie odcinają się zupełnie od społeczeństwa. Wniosek? Prawdziwy hikikomori latami nie chce opuszczać bezpiecznej ostoi, kontaktować się $\mathrm{z}$ rodziną i najbliższymi, a do porozumiewania się $\mathrm{z}$ otoczeniem stosuje Internet lub telefon. Wystawia w ten sposób sztukę jednego aktora i czterech ścian.

Na szczęście tę jednostkę chorobową można leczyć. Choć tak naprawdę rzadko, kiedy hikikomori powracają do normalności, terapia jest jak najbardziej możliwa i praktykowana. Stało się to możliwe dzięki zmianie nastawienia społeczeństwa do problemu. Niegdyś hikikomori był traktowany jak aspołeczna jednostka $\mathrm{z}$ marginesu, swoisty wybryk natury; teraz, w XXI w., przynajmniej w jakimś stopniu jest akceptowany w kolektywie Nihonu. Pojawia się coraz więcej klinik zajmujących się psychoterapią przypadków hikikomori. Szczególną rolę odgrywają ludzie, którzy po odpowiednim przeszkoleniu zajmują się negocjacjami z desperatem, mającymi z założenia nakłonić go do powrotu na łono społeczeństwa. Następują one osobiście lub poprzez Internet, w zależności od przypadku osobowego. Na ogół konieczny jest około roczny pobyt w ośrodkach reintegracyjnych. Skuteczność terapii szacuje się $\mathrm{w}$ przedziale od 30 do $70 \%$; wiele zależy jednak od charakteru leczonego. Istnieje możliwość samoczynnego wyrośnięcia z zachowań hikikomori, co pokazują statystyki: około 55\% Japończyków w wieku od 13 do 24 lat przejawiało niegdyś lub przejawia zachowania hikikomori. Nietrudno zatem wywnioskować, że można traktować wycofanie społeczne jako styl bycia; tymczasową modę, która przemija z wiekiem.

Temat dotarł już na łamy japońskiej popkultury. Sztandarową pozycją traktująca o hikikomori jest NHK ni yokoso! autorstwa Tatsuhiko Takimoto. Historia przedstawiona w książce została stworzona przez człowieka przejawiającego zachowania hikikomori; główny bohater, 21-letni Tatsuhiro Satō pozostaje w tym stanie cztery lata od przerwania studiów, czasem wychodząc jedynie po jedzenie. Pomimo prób pomocy rokowania są beznadziejne, zupełne wyle- 
czenie nie następuje. Bohater stacza się na dno; sięga po narkotyki, popada w obłęd. Powieść została zaadaptowana w formie 24-odcinkowej serii anime. Opowiada nie tylko o hikikomori, lecz również o otaku czy lolicon; porusza także problem internetowych samobójstw. Inne to postać Japonii w Axis Power Hetalia, gdzie okres sako$k u$ (izolacji) porównano wdzięcznie do hikikomori czy Kiri Komori $\mathrm{z}$ anime i mangi Sayonara Zetsubō Sensei, która też wycofała się społecznie.

Nieodłączne staje się pytanie: Czy to grozi Europie? Nie mi oceniać. Japońska mentalność jest na tyle odmienna od europejskiej, że mało prawdopodobne jest załapanie od nich wirusa hikikomori. Zbyt daleko przed nami są azjatyckie tygrysy, byśmy mieli je dogonić $\mathrm{w}$ tej chwili. Może kiedyś będziemy się z tym borykać? Na ten moment wystarczy, że mamy swoje problemy; nie będę wywoływać wilka $\mathrm{z}$ lasu. Jedno powiem na pewno: aspołeczność nie jest złem. Nie chodzi przecież o odrysowywanie od szablonu ludzi, lecz o wybór. Gorzej, jeżeli przychodzi nieproszona i jest przejawem złamania przez system. Póki co hikikomori to egzotyczny ptak. Warto jednak mieć świadomość, że w ogóle istnieje; od odrobiny wiedzy więcej jeszcze nikt się nie załamał. Chociaż... kto wie, jak to kiedyś będzie? 